\title{
A Mini-Review: Recent Advances in Coumarin-Metal Complexes With Biological Properties
}

\author{
Łukasz Balewski *, Sylwia Szulta, Aleksandra Jalińska and Anita Kornicka* \\ Department of Chemical Technology of Drugs, Faculty of Pharmacy, Medical University of Gdańsk, Gdańsk, Poland
}

The coumarin nucleus is a recurring motif in both natural and synthetic compounds that exhibit a broad spectrum of biological properties including anticoagulant, antiinflammatory, antioxidant, antiviral, antimicrobial and anticancer agents as well as enzyme inhibitors. On the other hand, it has been reported that the incorporation of a metal ion into coumarin derivatives can increase the activity of such complexes compared to coumarin-based ligands. Accordingly, some of them have been found to display promising antioxidant, antitumor or antibacterial activities. This mini-review briefly summarizes the recent development of coumarin-metal complexes with proven

OPEN ACCESS

Edited by:

Angela Stefanachi,

Angela Stefanachi, Italy

Reviewed by:

Clemens Zwergel,

Sapienza University of Rome, Italy

Balaji Babu,

Rhodes University, South Africa

*Correspondence:

Łukasz Balewski

lukasz.balewski@gumed.edu.pl

Anita Kornicka

anita.kornicka@gumed.edu.pl

Specialty section:

This article was submitted to

Medicinal and Pharmaceutical

Chemistry,

a section of the journal

Frontiers in Chemistry

Received: 23 September 2021 Accepted: 08 November 2021

Published: 01 December 2021

Citation:

Balewski Ł, Szulta S, Jalińska $A$ and Kornicka A (2021) A Mini-Review:

Recent Advances in Coumarin-Metal

Complexes With Biological Properties.

Front. Chem. 9:781779.

doi: 10.3389/fchem.2021.781779 biological properties. The attention is also paid to agents for which practical applications in the detection of biologically important species may be found.

Keywords: coumarin, $2 \mathrm{H}$-chromen-2-one, metal complexes, biological activity, fluorescent properties

\section{INTRODUCTION}

Coumarins belong to a family of large and extensively studied compounds containing $2 \mathrm{H}$-1benzopyran-2-one core structure, which consists of fused benzene and $\alpha$-pyrone rings. This heterocyclic system is also known as 1,2-benzopyrone, 2H-chromen-2-one, 2-oxo-1,2benzopyran or $o$-hydroxycinnamic acid lactone. The history of coumarins can be traced back to 1820 when H. A. Vogel first isolated the simplest member of this family coumarin from the tonka beans. Later on, this compound was first synthesized by W. M. Perkin in 1868. Both natural and synthetic coumarins are endowed with a great therapeutic potential due to the wide spectrum of biological properties including anticancer, antimicrobial, antiviral, anti-inflammatory, neuroprotective, and antioxidant activities. Hence, the coumarin skeleton can be foresighted as a privileged scaffold for the design and synthesis of pharmacologically active compounds (Pereira et al., 2018; Srikrishna et al., 2018; Stefanachi et al., 2018; Akkol et al., 2020; Al-Warhi et al., 2020; Garg et al., 2020; Mishra et al., 2020; Patel and Banerjee., 2020).

Additionally, physicochemical properties and biological activities of coumarins might be enhanced by combining coumarin moiety with other chemical species such as, for example, metal ions. The literature survey reveals that several properties of the organometallic complexes offer great opportunities in the development of new compounds with specific and new modes of action. In fact, incorporation of metals such as cobalt, copper, zinc, silver, platinum, palladium, or iridium, into ligand molecules with biological activity has been implemented in the development of novel coumarin-based complexes with better pharmacological activity. As a consequence, a large number of coumarin-based metal complexes have been synthesized in order to obtain more potent molecules (Gasser Metzler-Nolte N., 2012; Noffke et al., 2012; Ibrahim et al., 2019; Parveen et al., 2019; Boros et al., 2020). 


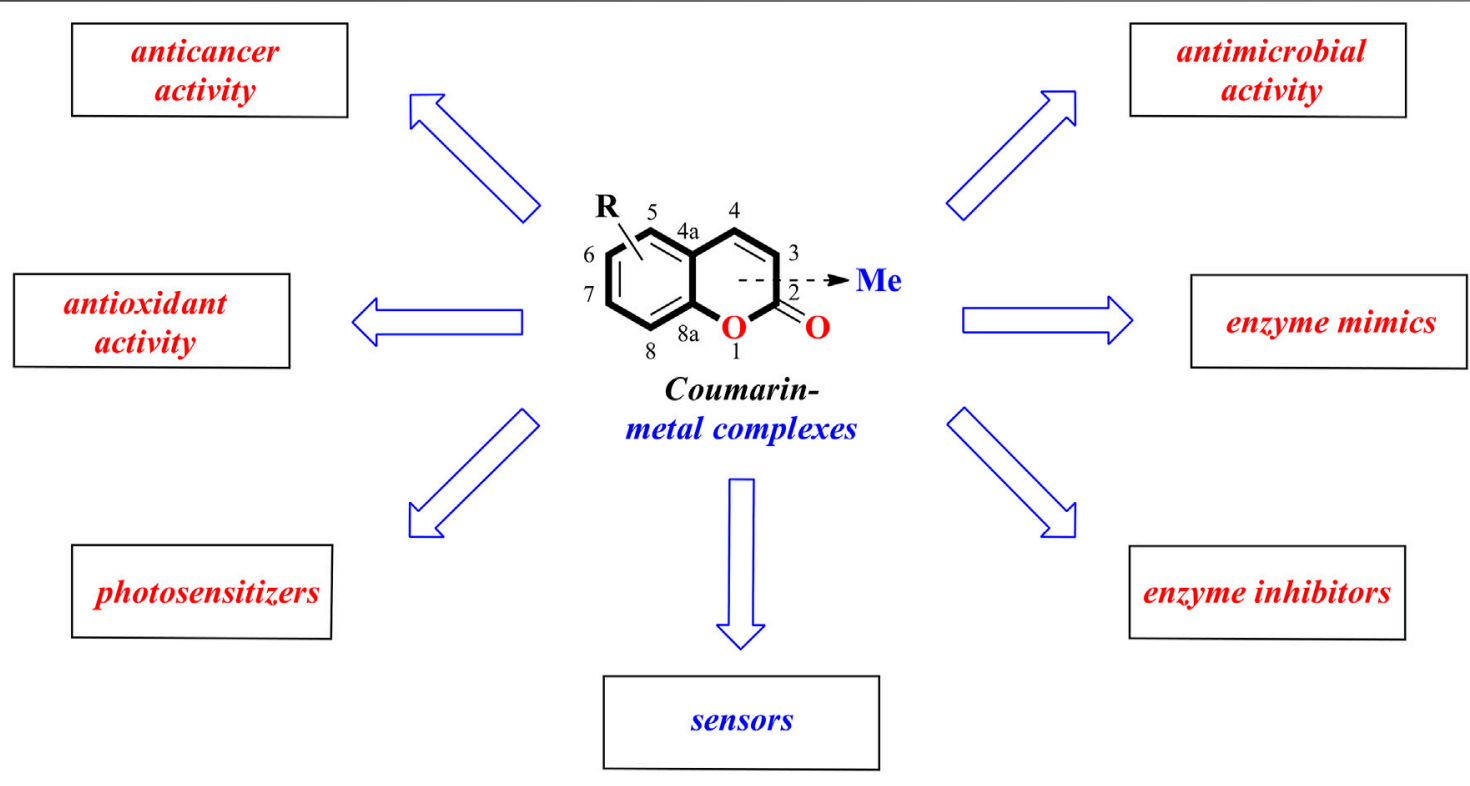

FIGURE 1 | Biological properties of coumarin-metal complexes.

To stay in line with the earlier described review works this mini-review is aimed at summarizing the recent advances in coumarin-metal complexes with anticancer, antibacterial, antioxidant, enzyme-mimicking, or enzyme-inhibiting activities as well as fluorescent properties during the period 2019-2021 (Figure 1) (Annunziata et al., 2020; Balcıoğlu et al., 2020; Song et al., 2020; Carneiro et al., 2021).

\section{ANTICANCER COMPLEXES}

Although there are many anticancer agents in medical practice, their use is associated with severe side effects and low efficacy. Therefore, the development of novel chemotherapeutics still remains an important area of antitumor drug design. An interesting therapeutically useful anticancer strategy consists in inhibiting cyclooxygenase (COX). On account of the crucial role of COX in cancerassociated inflammation, leading to the development and metastasis of malignancies, several COX-targeted inhibitors may serve as potential anticancer drugs.

In 2019, a series of bi-functional platinum (IV) complexes 1-4 (Table 1) with 7-hydroxycoumarin ligands in axial position were synthesized by Wang and collaborators and evaluated for their antitumor activity (Wang et al., 2019). Promising results were obtained for complex 3 which inhibits the rhCOX-2 activity from 20.1 to $65.8 \%$ in a dose-dependent manner. By releasing the appropriate derivative of coumaric acid, complex 3 reduces tumor-associated inflammation. Moreover, it was suggested that in cancers tissues the platinum (IV) complexes 1-4 may be reduced to an equivalent amount of platinum (II) compounds which exert DNA damage showing the bi-functional mechanism of action.
In the same year Gramni et al. designed and synthesized a new octahedral paramagnetic ruthenium (III) complex 5 of 4$\{[$ bis(pyridin-2-ylmethyl)amino]methyl $\}-7-m e t h o x y-2 H$-chromen2-one (chrdpa) (Table 1), whose structure was proved by X-ray crystallography and TOF-mass spectrometry. Compound $\mathbf{5}$ exhibited in vitro cytotoxic effect against cervical cancer cells (HeLa) with an estimated $\mathrm{IC}_{50}$ of $137 \mu \mathrm{M}$. (Gramni et al., 2019). DNA binding studies performed by titrating calf-thymus DNA with 5 revealed a distinctive hypochromic effect by $33 \%$ in the UV-Vis spectrum profile indicating that the ruthenium (III) complex $\mathbf{5}$ is a groove binding agent.

It is noteworthy that such chemical species as copper and cobalt are also valuable for the development of antitumor compounds. In 2020, Lu W. et al. disclosed the synthesis of novel coumarin-metal complexes which may be useful in the treatment of cervical cancer (Lu et al., 2020). The reaction of 8(tert-butyl)-3-(pyridin-2-yl)-2H-chromen-2-one with copper (II) nitrate trihydrate furnished the octahedral copper (II) complex 6 (Table 1) under mild reaction conditions, whose structure was unequivocally confirmed by a single-crystal X-ray diffraction analysis. This compound exhibited pronounced antiproliferative activity against the cervix tumor cell line (HeLa) with the $\mathrm{IC}_{50}$ value of $18.05 \mu \mathrm{M}$. Moreover, DNA binding studies revealed a hypochromic effect after adding DNA to the solution of complex 6, suggesting that this compound possesses an interactive mode of action.

Remarkable examples of novel cobalt (II) complexes have been presented by Mestizo and collaborators (Mestizo et al., 2021). Complexes 7 and 8 (Table 1) were synthesized starting from two tetradentate ligands bearing coumarin Schiff base $(\mathrm{R}=$ $\mathrm{H}, \mathrm{OCH}_{3}$ ) and further evaluated against human cervical epithelioid carcinoma cell line (HeLa) and non-carcinogenic human cell lines (HFF-1 and $\mathrm{HaCaT}$ ). The results of the in vitro 
TABLE 1 | Coumarin-based metal complexes with diverse biological activities.<smiles>Cc1cc(=O)oc2cc(OC(=O)O[Te](N)(N)(Cl)(Cl)OC(=O)Oc3ccc4c(C)cc(=O)oc4c3)ccc12</smiles>

$\begin{array}{lll}\text { 1: } n=1 & \text { rhCOX-2 } & \text { Wang,et al. } \\ \text { 2: } n=3 & \text { inhibitors } & \text { (2019) }\end{array}$

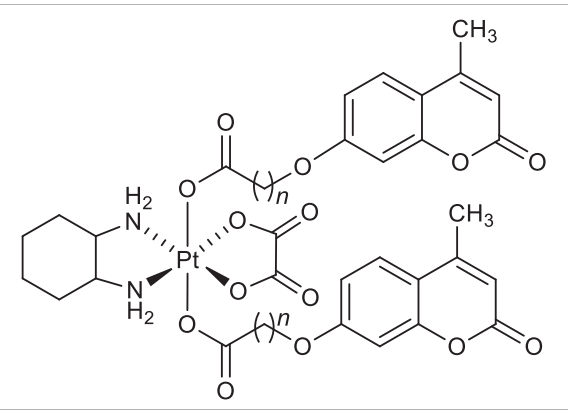

$\begin{array}{lll}\text { 3: } n=1 & \text { rhCOX-2 } & \text { Wang,et al. } \\ \mathbf{4}: n=3 & \text { inhibitors } & \text { (2019) }\end{array}$<smiles>COc1cccc2cc3oc(=O)cc(c-2cc1)CN(Cc1ccccn1)C3(Cl)Cl</smiles><smiles></smiles><smiles></smiles>

7: $\mathrm{R}=\mathrm{H}$ 8: $\mathrm{R}=\mathrm{OCH}_{3}$ cervical cancer cell line (HeLa),generation of ROS
Mestizo et al. (2021) 
TABLE 1 | (Continued) Coumarin-based metal complexes with diverse biological activities.

Chemical structure

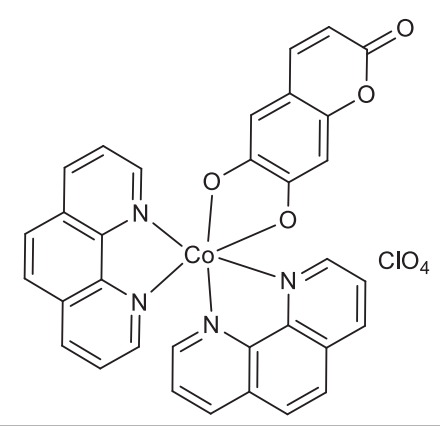

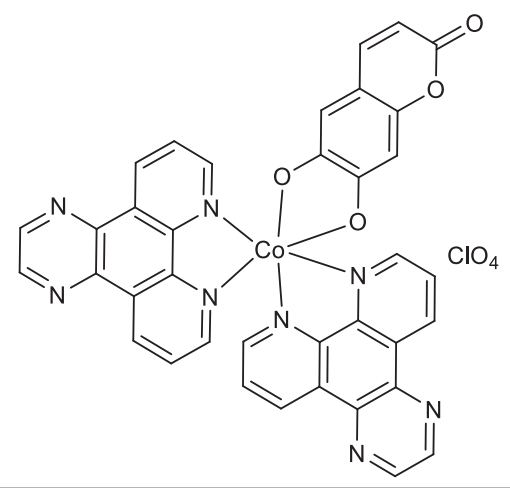

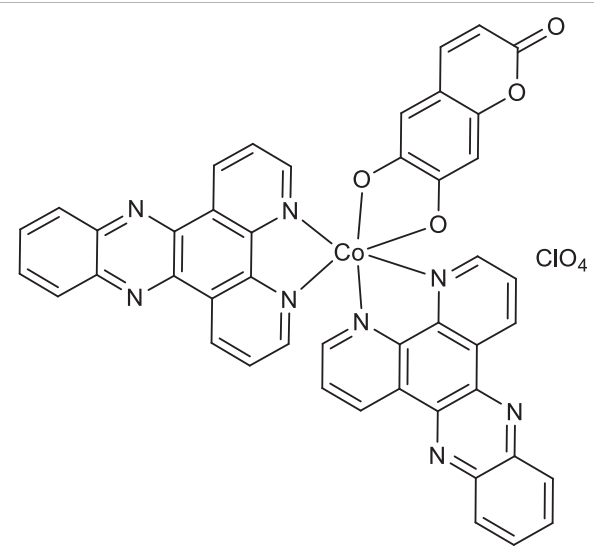

11
References

cervical cancer cell line (HeLa) and Sarkar et al. human breast cancer cell line (2021) (MCF-7) cervical cancer cell line (HeLa) and human breast cancer cell line (MCF-7)
10

human breast cancer cell line
(MCF-7)

Sarkar et al. (2021) cervical cancer cell line (HeLa) and human breast cancer cell line (MCF-7)
Sarkar et al. (2021)

\section{Antibacterial complexes}<smiles>N[W](N)(Cl)(Cl)(Cl)OC(=O)c1cc2ccccc2oc1=O</smiles>

12: $\mathrm{M}=\mathrm{Cu}$

13: $M=Z n$
Staphylococcus aureus (ATCC 25923)
Belkhir-Talbi et al. (2019)<smiles></smiles>

B. animalis subsp. lactis, $P$. aeruginosa, E. coli
Avdović et al. (2019) 
TABLE 1 | (Continued) Coumarin-based metal complexes with diverse biological activities.

\section{Chemical structure}<smiles>CCN(CC)c1ccc2cc(C(=O)NC(C)(Cl)C(C)(Cl)Cl)c(=O)oc2c1</smiles>

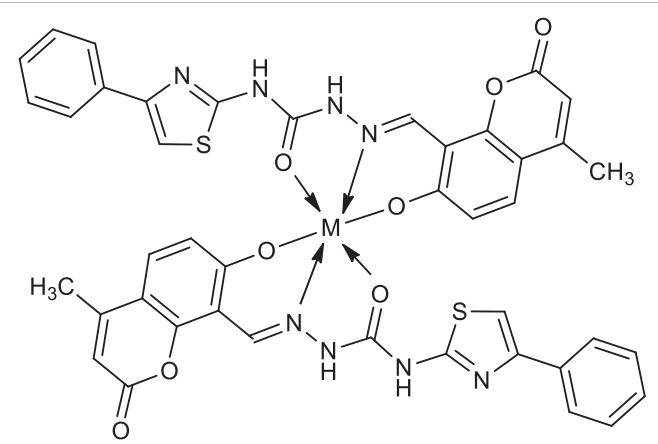

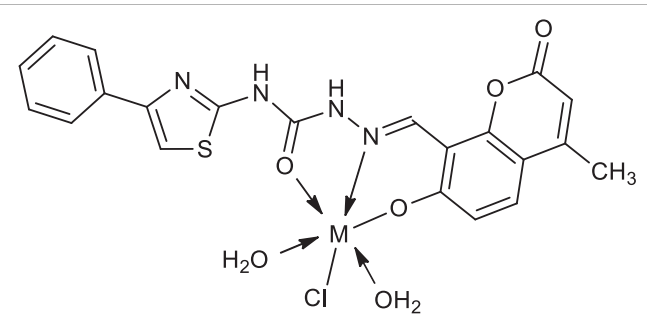<smiles>COC12OCN1C(=C(C)c1cc3ccccc3oc1=O)N=C(c1ccc(O)cc1)O2</smiles><smiles>CCN(CC)c1ccc2cc(/C(C)=N/N=C3/C(c4cccc(OC)c4)=NN(C)C34CO4)c(=O)oc2c1</smiles>

\section{Number of complex}

15: $\mathrm{R}=\mathrm{H}$

16: $\mathrm{R}=\mathrm{Cl}$

17: $\mathrm{R}=\mathrm{Br}$

18: $\mathrm{R}=\mathrm{OCH}_{3}$
Target/Activity

References

De Almeida et al. (2019)
19: $M=C O$

20: $\mathrm{M}=\mathrm{Ni}$
Bacillus subtilis, Staphylococcus aureus, Salmonella typhi
Yernale et al. (2020) 
TABLE 1 | (Continued) Coumarin-based metal complexes with diverse biological activities.

\section{Chemical structure}<smiles></smiles>

Number of complex

27: $R^{1}=H ; R^{2}=H$

28: $\mathrm{R}^{1}=\mathrm{Cl} ; \mathrm{R}^{2}=\mathrm{H}$

29: $R^{1}=H ; R^{2}=C l$
Target/Activity

References

SARS-CoV-2 main protease

Milenković et al. (2020)

\section{Antioxidant complexes}<smiles>[R][X]c1cccc2oc(=O)cc(CN3C=NN(CC=C)C3[Z19]3CN(CC=C)N=CN3Cc3cc(=O)oc4ccccc34)c12</smiles>
30: $\mathrm{R}=6-\mathrm{CH}_{3}$
DPPH-based radical scavenging
32: $\mathrm{R}=6-\mathrm{Cl}$
$\mathrm{B3}=7,8$-benzo
activity
Geetha and
Narayana et al.

33: $R=7,8$-benzo<smiles>[R][R]c1ccc2oc(=O)cc(CN3N=CN(c4c(C)cccc4C)C3[Ga]C3N(Cc4cc(=O)oc5ccccc45)C=NN3c3c(C)cccc3C)c2c1</smiles><smiles></smiles> 
TABLE 1 | (Continued) Coumarin-based metal complexes with diverse biological activities.

\section{Chemical structure}

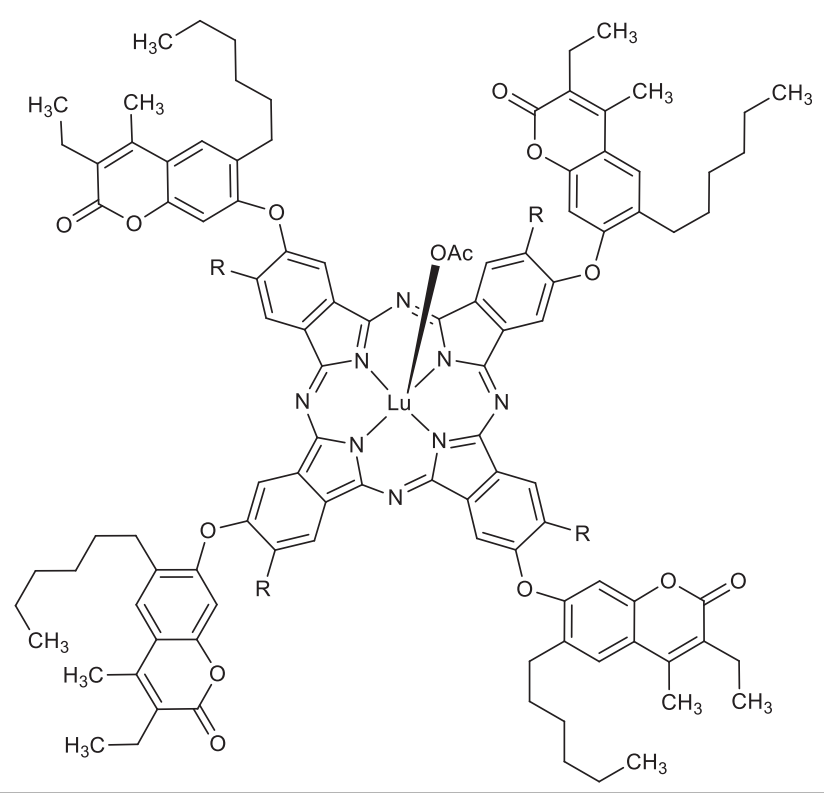

Number of complex

36: $\mathrm{R}=\mathrm{Cl}$

37: $\mathrm{R}=$

$\mathrm{CH}_{3}$<smiles>CCCCc1cc2c(C)c(CC)c(=O)oc2cc1O</smiles>
References
Özdemir and
Köksoy. (2020)
(20)

\section{Complexes as photosensitizers in photodynamic therapy}

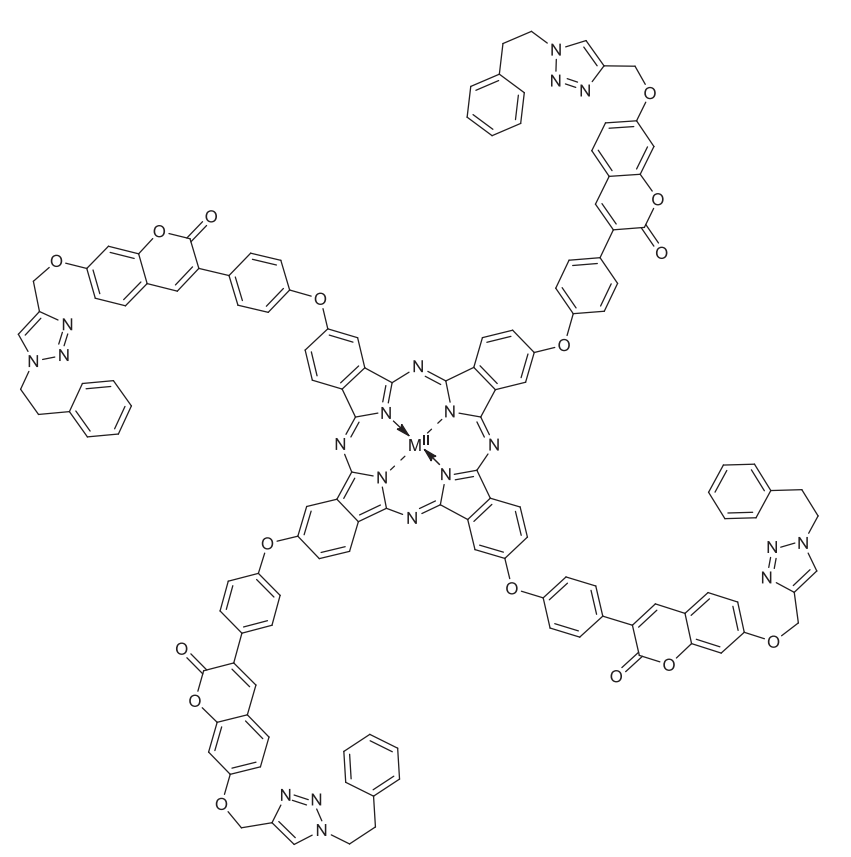
38: $M^{\prime \prime}=Z n$
39: $\mathrm{M}^{\prime \prime}=\mathrm{Mg}$ (peripheral)

radical cation scavenging activity

Target/Activity

(

)


TABLE 1 | (Continued) Coumarin-based metal complexes with diverse biological activities.

\section{Chemical structure}

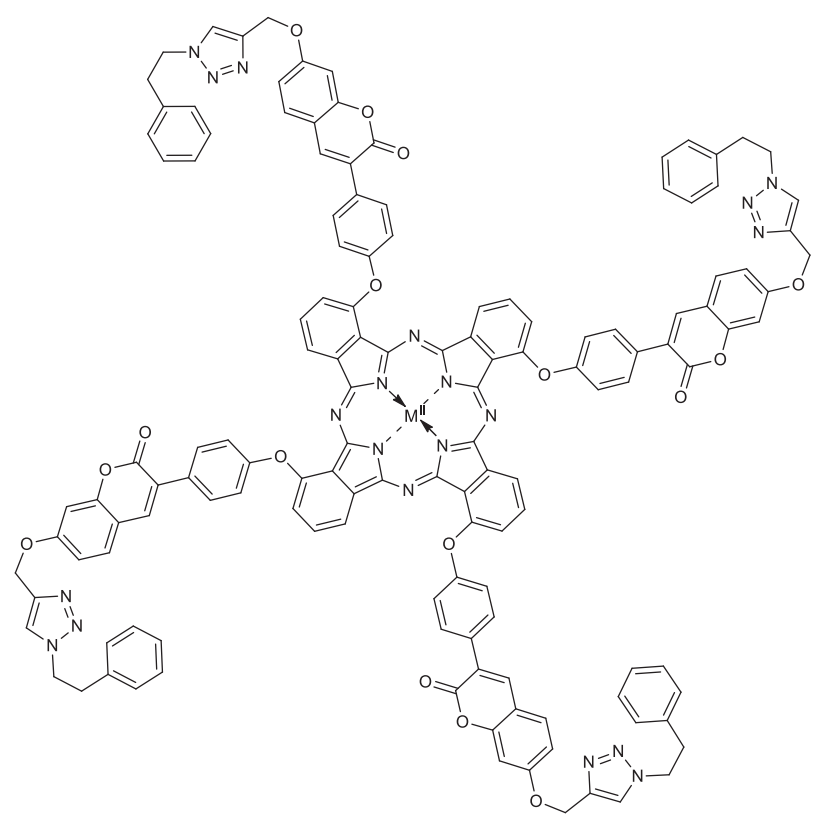

Number of complex

40: $M^{\prime \prime}=\mathrm{Zn}$

41: $M^{\prime \prime}=M g$

(non-peripheral)
Target/Activity

type II photosensitizers in photodynamic therapy
References

Özdemir and

Abliatipova.

(2020)

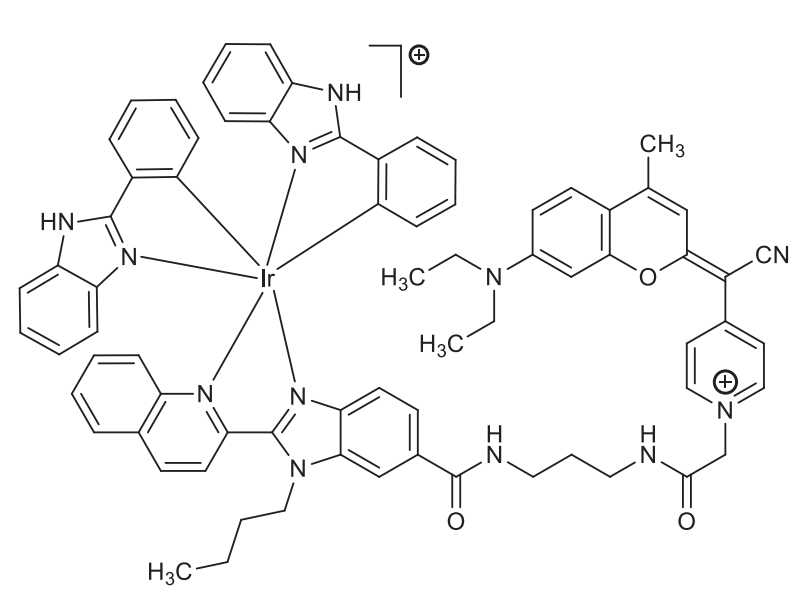

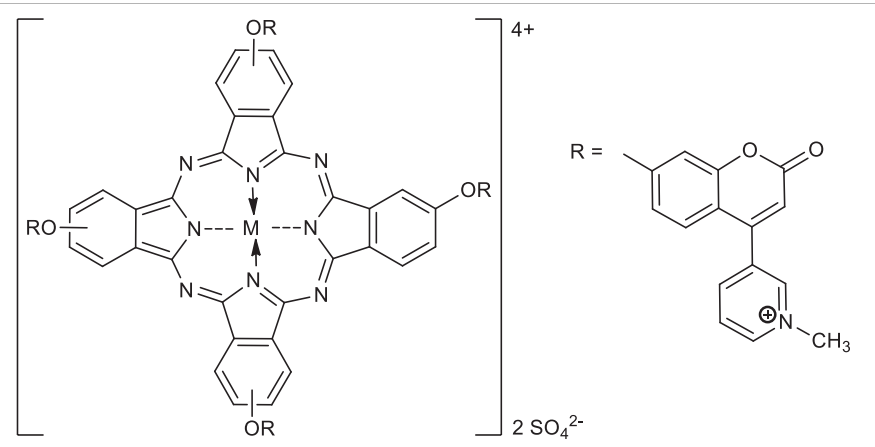

42: $M=Z n$

43: $\mathrm{M}=\operatorname{lnCl}$

44: $M=M g$ photosensitizers in photodynamic therapy
Boyar Çamur.

(2019)

\section{8 \\ Ir(III)-COUPY-conjugate}

photosensitizer in photodynamic therapy of cancer: cervical cancer cells (HeLa), prostatic cancer stem cells DU145
Novohradsky and Rovira. 2019 Novohradsky and Markova. (2021) 
TABLE 1 | (Continued) Coumarin-based metal complexes with diverse biological activities.

Chemical structure

Number of complex

Enzyme-mimicking complexes<smiles>CO[V](=O)(O)(OC)Oc1ccc2c(C)cc(=O)oc2c1/C=N/c1ccccc1O</smiles>

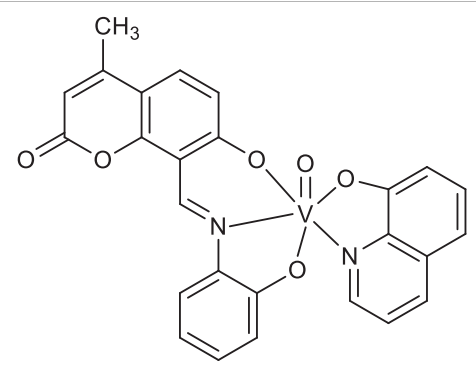

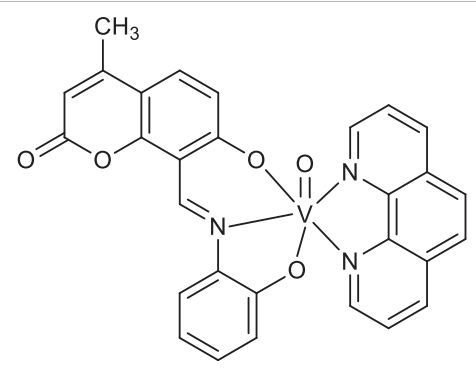

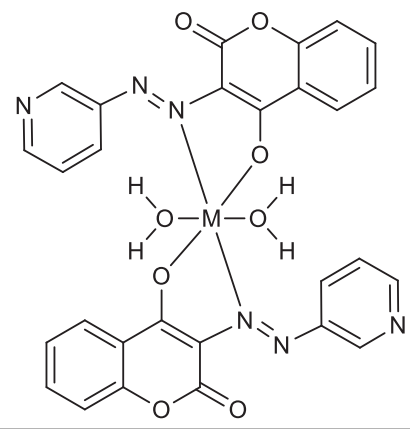

Enzyme inhibiting complexes

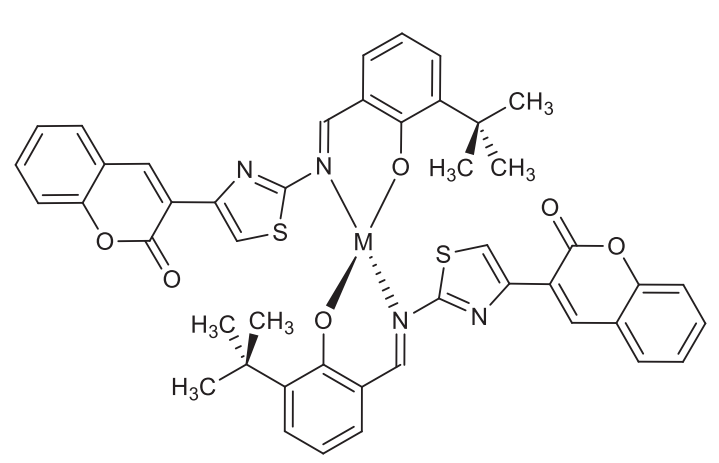

Target/Activity

References

\begin{tabular}{|c|c|c|}
\hline 49 & $\begin{array}{l}\text { halo-peroxidase mimicking } \\
\text { properties }\end{array}$ & $\begin{array}{l}\text { Majumder and } \\
\text { Rajak. (2020) }\end{array}$ \\
\hline
\end{tabular}

50

$\begin{array}{ll}\text { halo-peroxidase mimicking } & \text { Majumder and } \\ \text { properties } & \text { Rajak. (2020) }\end{array}$

$\begin{array}{lll}51 & \text { halo-peroxidase mimicking } & \text { Majumder and } \\ \text { properties } & \text { Rajak. (2020) }\end{array}$

$\begin{array}{lll}\text { 52: } M=\mathrm{Cu} & \text { catecholase-like or } & \text { Sezgin et al. } \\ \text { 53: } M=\mathrm{Mn} & \begin{array}{l}\text { phenoxazinone synthase } \\ \text { mimicking properties }\end{array}\end{array}$


TABLE 1 | (Continued) Coumarin-based metal complexes with diverse biological activities.

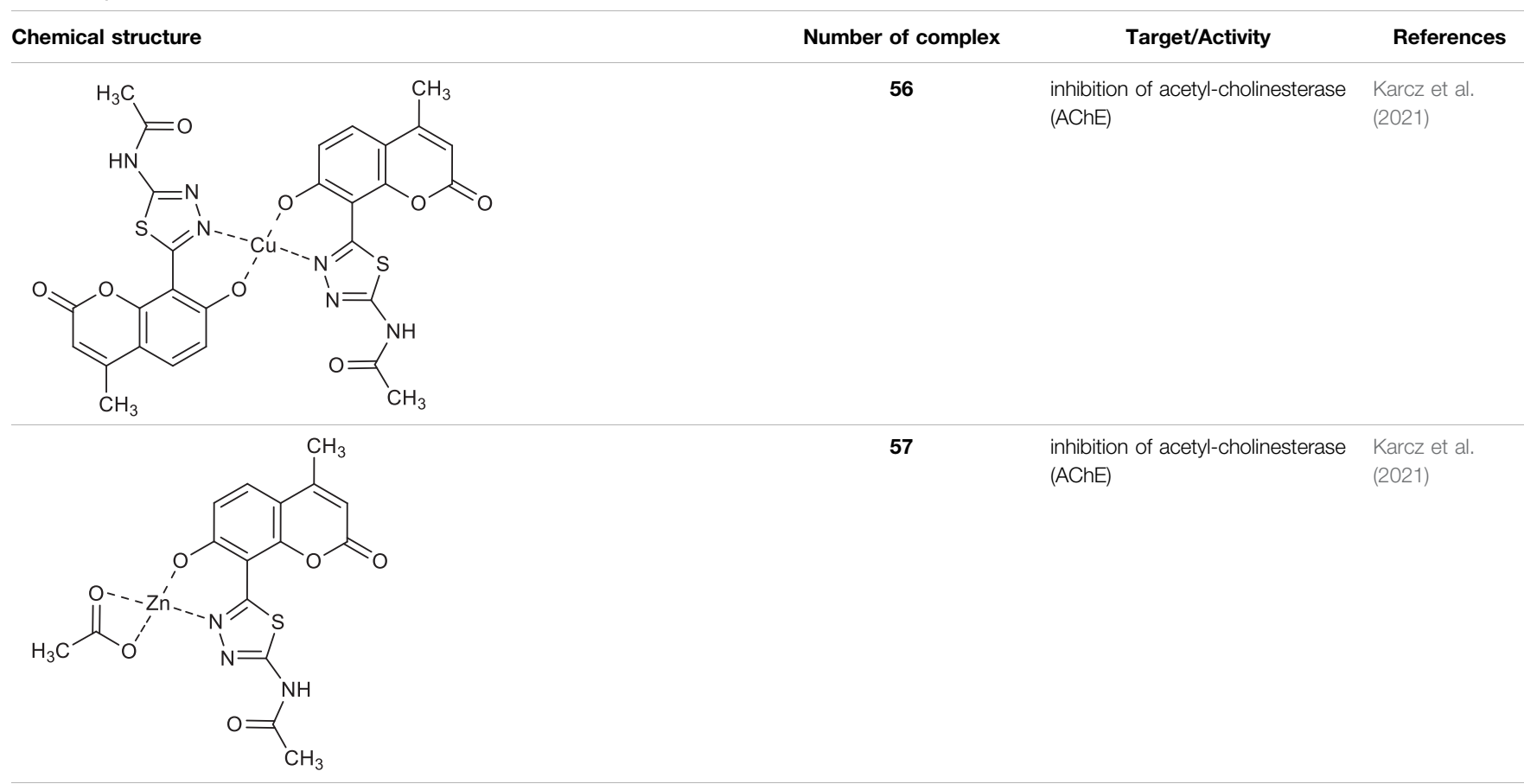

study showed that cytotoxicity of $\mathbf{7}$ and $\mathbf{8}$ against HeLa cell line is higher than that of cisplatin with calculated $\mathrm{IC}_{50}$ values of 3.5 and $4.1 \mu \mathrm{M}$, respectively. Concerning the mechanism of action, it was explained that their anticancer potential on HeLa cells may be a result of the generation of reactive oxygen species (ROS).

Worth noting are cobalt (III) complexes $\left[\mathrm{Co}(\mathrm{B})_{2}(\mathrm{~L})\right] \mathrm{ClO}_{4}$ 911 (Table 1) prepared by Sakar and co-workers in a two-step procedure, starting from $N, N$-donor bases: 1,10-phenanthroline (phen), dipyrido [3,2-days: $\left.2^{\prime}, 3^{\prime}-f\right]$ quinoxaline $(d p q)$ or dipyrido $\left[3,2-a: 2^{\prime}, 3^{\prime}-c\right]$ phenazine base $(d p p z)$ and naturally occurring esculetin (6,7-dihydroxycoumarin) as dianionic $O, O$-donor, as well as cobalt (II) chloride and sodium perchlorate in the presence of triethylamine (Sarkar et al., 2021). These new complexes, due to their high visible light-triggered cytotoxicity against cervical cancer cell line (HeLa) and human breast cancer cell line (MCF7 ), represent an interesting example of potent next-generation photochemotherapeutics. Moreover, complex 11 exerted a remarkable activity and negligible toxic effect in the dark, and binds with the greatest affinity to calf-thymus DNA. It was concluded that the observed photocleave of supercoiled DNA properties of this compound is connected with the formation of hydroxyl radicals from superoxide radicals via a type 1 photoredox reaction.

\section{ANTIMICROBIAL COMPLEXES}

With the rise of resistance to commonly used antibiotics, there is a need for novel therapeutic agents and drugs. It should be noted that therapeutic options for many bacteria strains are still limited and the research aimed at discovering new antimicrobial drugs has been focused on the design of metal complexes. Valuable information regarding antimicrobial metal complexes of coumarins can be found in recently published papers. These compounds are predicted to synergize with conventional antimicrobial drugs by binding to DNA or inhibiting DNA replication and biosynthesis (Claude et al., 2020; Frei., 2020).

In 2019, Belkhir-Talbi et al. described copper (II) and zinc(II) complexes of 3-(2-hydroxybenzoyl)-2H-chromen-2-one 12 and 13 (Table 1) as effective agents against Gram-positive bacteria strain: Staphylococcus aureus (ATCC 25923) (Belkhir-Talbi et al., 2019). It was found that both complexes exhibited moderate antibacterial activity and diameters of inhibition zones were in the range of $14-17 \mathrm{~mm}$ in comparison to reference secondgeneration cephamycin group antibiotic - cefoxitin (diameter of inhibition zone: $20 \mathrm{~mm}$ ). Furthermore, complexes 12 and 13 showed a higher scavenging activity in comparison to the free ligand. The favorable in silico ADMET and drug-likeness profile of these compounds confirmed their non-toxic and noncarcinogenic properties.

Avdović et al. designed a series of five palladium (II) complexes with 3-[1-(2-hydroxypropylamino)ethylidene] chroman-2,4-dione, 3-[1-(phenylamino)ethylidene]chroman2,4-dione, 3-[1-(o-toluidino)ethylidene]chroman-2,4-dione, 3[1-( $m$-toluidino)ethylidene]-chroman-2,4-dione, and 3-[1-(2mercaptoethylamino)ethylidene]chroman-2,4-dione in order to evaluate their antimicrobial activity (Avdović et al., 2019). In general, the activity of the complexes was higher or similar to that of the corresponding ligands. Among them, Pd(II) complex 14 (Table 1) was found to be more active against Bifidobacterium animalis subsp. lactis, Pseudomonas aeruginosa, Escherichia coli than the reference ligand - 3-[1-(2-hydroxypropylamino) 
TABLE 2 | Coumarin-based metal complexes as fluorescent probes/sensors.

Chemical structure

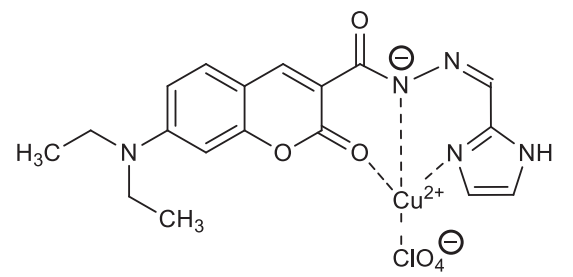<smiles>O=C(NN=C(c1ccccc1)c1cc2ccc(O)cc2oc1=O)OC1=Cc2ccc(O)cc2OC1=C(c1ccccc1)c1cc2ccccc2c(=O)n1NC(=O)c1ccccc1</smiles>

Application

Number of

complex

58
References

He et al. (2019)<smiles></smiles>

60: $\mathrm{R}=\mathrm{OH} \quad$ detection of water

61: $\mathrm{R}=\mathrm{N}\left(\mathrm{C}_{2} \mathrm{H}_{5}\right)_{2}$ detection of cysteine (Cys), homocysteine (Hcy), Li et al. (2019) and glutathione (GSH)
Cheng et al.

(2019)

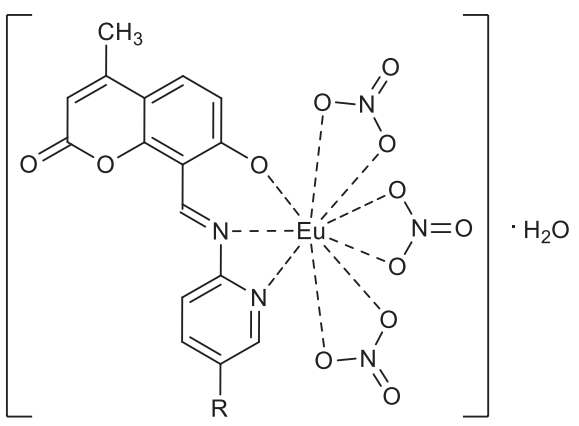

62: $\mathrm{R}=\mathrm{H}$ 63: $\mathrm{R}=\mathrm{OCH}_{3}$

64: $\mathrm{R}=\mathrm{NO}_{2}$ 
TABLE 2 | (Continued) Coumarin-based metal complexes as fluorescent probes/sensors.

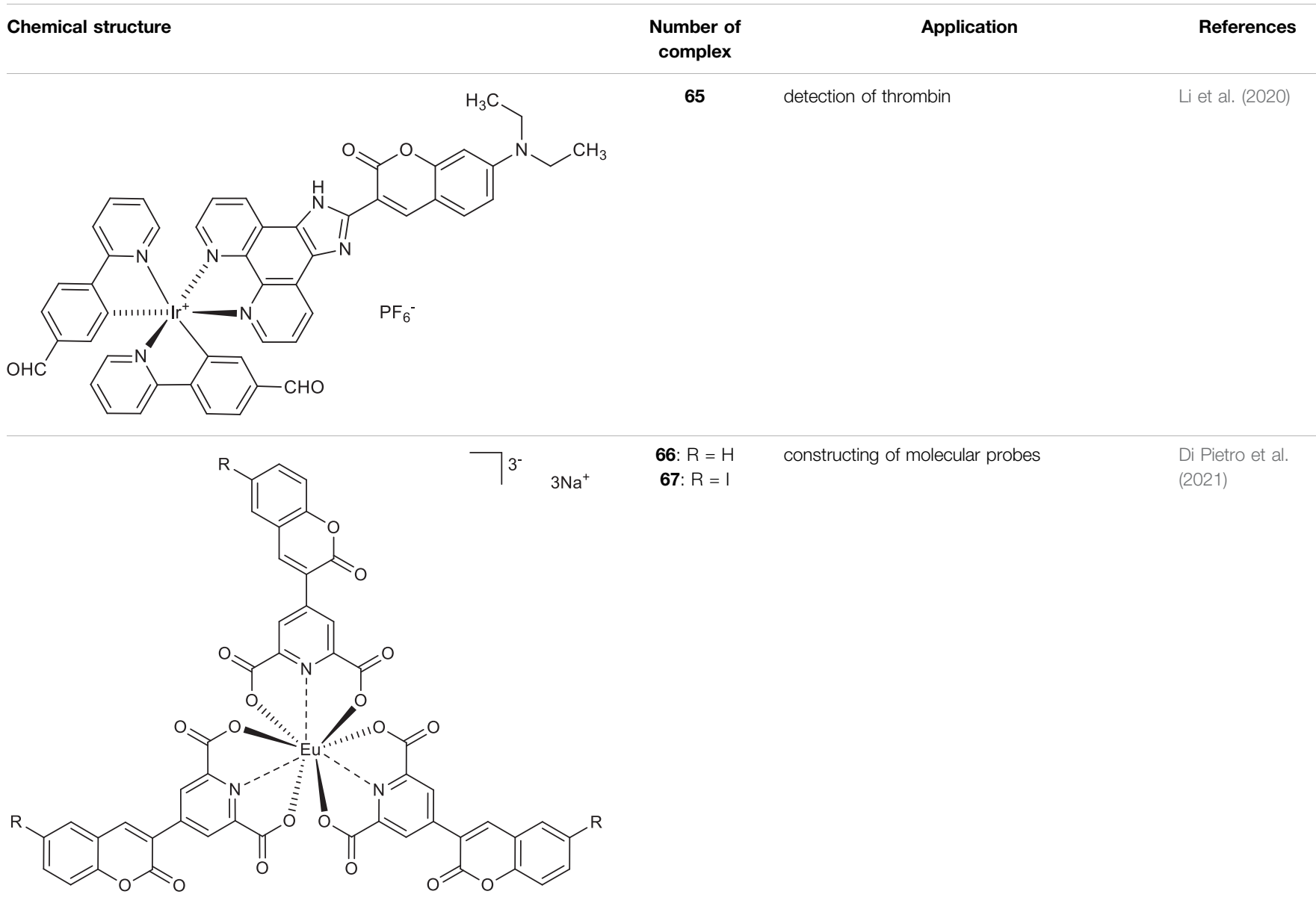

ethylidene]chroman-2,4-dione and other complexes, showing favourable MIC and MMC values (500 and $1,000 \mu \mathrm{g} / \mathrm{ml}$ ) towards probiotic bacteria - Lactobacillus plantarum. Moreover, complex 14 resulted to be more potent as fungicide compared with fluconazole, exhibiting a selective activity against Aspergillus flavus ATCC 9170 (MIC $=62.5 \mu \mathrm{g} / \mathrm{ml}$ ). It was suggested that the promising antifungal activity of the complex 14 may be attributed to the presence of palladium (II) as well as hydroxypropylimine moiety.

In the same year, Almeida and collaborators synthesized a series of ruthenium (II)-DMSO complexes containing coumarin- $N$-acylhydrazone hybrids 15-18 (Table 1), whose antibacterial properties were evaluated (De Almeida et al., 2019). Investigation of biological activity revealed that the antibacterial potency of these compounds is higher than the free ligands and related to the lipophilicity (as indicated by the presence of chlorine and bromine atoms in substitution pattern), and charge of the complex. Among them, the transdichloro-cis-bis(dimethylsulfoxide)-(Z)- $N^{\prime}$-4-bromobenzylidene7-(diethylamino)-2-oxo- $2 \mathrm{H}$-chromene-3-carbhydrazide ruthenium (II) 17 (Table 1) turned out to be the most promising with MIC value of $31.24 \mu \mathrm{g} / \mathrm{ml}$ against Staphylococcus aureus. Surprisingly, further studies against tumor cell lines demonstrated that the potency of free ligands upon chelation was decreased.

In 2020, Yernale et al. evaluated the antimicrobial effects of a series of octahedral $\mathrm{Co}$ (II) 19, $\mathrm{Ni}$ (II) 20, Cu(II) 21, and $\mathrm{Zn}$ (II) 22 (Table 1) complexes with coumarin-derived Schiff base ligand 2[(7-hydroxy-4-methyl-2-oxo-2H-chromen-8-yl)methylene]- $\mathrm{N}$ (4-phenylthiazol-2-yl)hydrazinecarboxamide against bacteria strains: Bacillus subtilis, Staphylococcus aureus, Escherichia coli, Salmonella typhi and prominent fungal pathogens: Candida albicans, Aspergillus flavus, Cladosporium oxysporum, Aspergillus niger (Yernale et al., 2020). According to the chelation theory, upon coordination of the metal ion to the ONO donor atoms Schiff base, all synthesized complexes were more active than the corresponding ligand as a result of the lipophilic character of chelate. This may promote the permeation of complexes through the membranes, blocking binding sites of the bacterial enzymes. Furthermore, the results of DNA cleavage studies showed that these newly synthesized complexes possess the ability to carry out an efficient cleavage of the supercoiled plasmid DNA pBR322, which suggests that these compounds constitute promising pathogenic microorganism inhibitors.

Most recently, according to the Nongpiur and collaborators report a half-sandwich complexes of platinum group metals were 
invented as antibacterial agents (Nongpiur et al., 2021). The complexes of $\operatorname{Ir}(\mathrm{III}), \mathrm{Ru}(\mathrm{II})$, and $\mathrm{Rh}(\mathrm{III})$ with coumarin- $N$ acylhydrazone-based ligands 23-26 (Table 1) have shown promising activities towards Gram-positive bacterial strains: Staphylococcus aureus and Bacillus thuringiensis with MIC in the range of $1.25-2.5 \mathrm{mg} / \mathrm{ml}$ and the inhibition zones in the range of $18-19 \mathrm{~mm}$. The presence of the electron-donating groups $\mathrm{N}\left(\mathrm{C}_{2} \mathrm{H}_{5}\right)_{2}$ or $\mathrm{OCH}_{3}$ in the structure of these complexes might be contributed to increased antibacterial activity. Additionally, the evaluation of redox properties of these compounds showed their moderate to high radical scavenging activity (50.6-85\%). In this context, described platinum group metal complexes of coumarins are also worth mentioning as potential antioxidants which can neutralize the free radicals and inhibit the propagation of the chain reactions.

With regards to the antimicrobial activity of coumarin-based complexes some studies have been recently carried out showing the potential of palladium (II) complexes as antiviral agents. Milenković and co-workers have studied in silico a series of palladium (II) complexes 27-29 (Table 1) as potent inhibitors of the main protease $\left(\mathrm{M}^{\mathrm{pro}}\right)$ of severe acute respiratory betacoronavirus (SARS-CoV-2) (Milenković et al., 2020). The computational studies showed that the binding affinities of complexes 27-29 were higher $\left(K_{\mathrm{i}}=2.33 ; 7.55 ; 17.94 \mathrm{nM}\right)$ than those obtained for two potential SARS-CoV-2 $\mathrm{M}^{\text {pro }}$ inhibitors cinanserin and chloroquine $\left(K_{\mathrm{i}}=256.8 \mathrm{nM}\right.$, and $629.1 \mathrm{nM}$, respectively). Moreover, the generated binding free energy of complex 28 is significantly high $\left(\Delta G_{\text {binding }}=-149.7 \mathrm{~kJ} / \mathrm{mol}\right)$ compared to the values of the free ligand $\left(\Delta G_{\text {binding }}=\right.$ $-62.1 \mathrm{~kJ} / \mathrm{mol})$ and reference cinanerin $\left(\Delta G_{\text {binding }}=-49.8 \mathrm{~kJ} /\right.$ mol). Based on the promising molecular docking results, it was claimed that further experimental studies should be undertaken to verify these predictions.

\section{ANTIOXIDANT COMPLEXES}

The antioxidant potential of coumarin-metal complexes has been investigated in recent years and it was presented that they have a special ability to scavenge reactive oxygen species in biological systems. The uncontrolled production of reactive oxygen species (ROS) is associated with many pathologies such as tumors, neurodegenerative diseases, sickle cell anaemia, or thalassemia. However, these disorders may be treated using compounds with free radicals scavenging properties, which at the same time possess the ability to protect the normal blood cells. In this context, the hematologic cancers therapeutic strategy requires antioxidants combating the tumor cells and exhibiting high compatibility with erythrocytes. Additionally, some of them possess potential antihaemolytic properties.

In 2020, Geetha and others evaluated three series of silver(I) complexes of coumarin and allyl substituted NHC ligands derived from 1,2,4-triazole for their antioxidant properties (Geetha and Narayana., 2020). However, all the complexes displayed much better DPPH-based radical scavenging activity compared with silver nitrate and a representative triazolium hexafluorophosphate salt, bis-NHC coordinated silver hexafluorophosphate complexes 30-32 (Table 1) evidenced higher activity than other members of the tested complexes. The best result was found for complex $\mathbf{3 0}$ with an $\mathrm{IC}_{50}$ value of $61 \mu \mathrm{M}$. In addition, at a concentration of $100 \mu \mathrm{M}$ complexes 30-32 exhibited lysis of red blood cells as low as $2.32 \%$. Efforts to obtain even more potent bioactive agents have led to new $\mathrm{Ag}(\mathrm{I})-\mathrm{NHC}$ complexes derived from coumarin substituted 4-aryl1,2,4-triazol-5-ylidenes 33 and 34 (Table 1) which displayed antioxidant potencies with the $\mathrm{IC}_{50}$ values of 7.49 and $7.42 \mu \mathrm{M}$, respectively, and at the concentration of $100 \mu \mathrm{M}$ showed cell lysis of human red blood cells in the range of 3.50-4.38\% (Geetha and Małecki., 2020).

Recently, it was demonstrated, that chemotherapeutic properties of coumarin-3-carboxylic acid (2-oxo-2H-1benzopyran-3-carboxylic acid, HCCA) may be increased by metal chelation. One example is the coordination of HCCA with a silver(I), which was proved to enhance its antimicrobial activity. Such promising biological activity of HCCA and its complexes prompted their further investigations. For this reason, the antioxidant activity of transition metal complexes of HCCA has been screened via the 2,2-diphenyl-1picrylhydrazyl (DPPH) method by De Souza and co-workers (Souza et al., 2021). The best radical scavenging properties have been shown by copper (II) complex 35 (Table 1), which exhibited $31 \%$ of inhibition of free radicals at a concentration of $160 \mu \mathrm{M}$.

Another example of promising antioxidants represents synthesized in 2020 by Özdemir et al. novel 7-oxy-3-ethyl-6hexyl-4-methylcoumarin substituted lutetium (III) phthalocyanine compounds (Özdemir and Köksoy., 2020). The radical cation scavenging activities of complexes 36 and 37 (120.344 mM trolox $/ \mathrm{mg}$ and $188.733 \mathrm{mM}$ trolox $/ \mathrm{mg}$, respectively) (Table 1) were significantly higher than the values for standard BHA - butylated hydroxyanisole (52.63 $\mathrm{mM}$ trolox/mg) in 2,2' -azino-bis-3-ethylbenzothiazoline6-sulfonic acid (ABTS) analysis.

\section{COMPLEXES AS PHOTOSENSITIZERS IN PHOTODYNAMIC THERAPY}

Photodynamic therapy (PDT), an important strategy for anticancer treatment, involves specific compounds called photosensitizers, oxygen, and light irradiation at an appropriate wavelength to induce the production of high levels of singlet oxygen by photosensitizer. Effective photosensitizers should also exhibit required stability to not decay after light exposure in photodegradation phenomenon. The increase of singlet oxygen or other reactive oxygen species may promote oxidative stress and apoptosis of cancer cells with low ROS levels (Kim et al., 2013; Qian et al., 2018).

In 2020, Özdemir and co-workers exploited the copper(I)catalyzed azide-alkyne Huisgen 1,3-dipolar cycloaddition reaction to obtain the first example of phthalocyaninecoumarin derivatives bearing triazole ring, which constitute the direct precursors of peripheral 38-39 or non-peripheral 40-41 zinc(II) and magnesium (II) phthalocyanines (Zn-Pcs or Mg-Pcs) (Table 1) (Özdemir and Köksoy., 2020). The 
photophysical and photochemical studies revealed that complexes 38-41 may be used as type II photosensitizers in photodynamic therapy because the singlet oxygen quantum yields $\left(\Phi_{\Delta}\right)$ ranged in acceptable values from 0.17 to 0.49 ; the highest $\Phi_{\Delta}$ value was observed for the peripheral zinc phthalocyanine $38\left(\Phi_{\Delta}=0.489\right.$ in DMSO). Moreover, magnesium-Pc 39 showed an acceptable value of the fluorescence quantum yield $\Phi_{\mathrm{F}}=0.31$. At this point it should be mentioned, that $\Phi_{\Delta}$ values of metal-free coumarin/triazole phthalocyanine compounds were obtained as quite low.

The encouraging results in the perspective of using metal complexes of highly water-soluble quaternized ionic phthalocyanines 42-44 and 45-47 (Table 1) as promising photosensitizers for photodynamic therapy were obtained by Boyar and Çamur (Boyar and Çamur. 2019). The highest singlet oxygen quantum yields in the presence of Triton X100 exhibited peripherally substituted $\operatorname{In}(\mathrm{III}) \mathrm{Pc} 43\left(\Phi_{\Delta}=\right.$ $0.93)$ and non-peripherally substituted - $\mathrm{Zn}(\mathrm{II}) \mathrm{Pc} 45\left(\Phi_{\Delta}=\right.$ $0.92)$, and $\operatorname{In}(\mathrm{III}) \mathrm{Pc}\left(\Phi_{\Delta}=0.41\right)$. Moreover, complexes of Pcs 42-44 and 45-47 readily bind to bovine serum albumin, which suggests that they will be carried in the bloodstream similar to drugs.

Commonly used chemotherapeutics in the treatment of an advanced prostate cancer exhibit several disadvantages and possess limited efficiency to target cancer stem cells (CSCs). The CSCs are considered the main reason for tumor metastasis and antitumor drugs resistance. Moreover, these cancer stem cells characterize the low levels of ROS. In this context, the strategy of stimulation of production of several types of ROS may be beneficial in the treatment of aggressive and even hardly treatable cancer stem cells. Novohradsky and co-workers have described a cyclometalated iridium (III) complex 48 conjugated with novel class of far-red/NIR-emitting fluorophore (COUPY), in which carbonyl group of coumarin core was replaced with $\mathrm{N}$-alkylated cyano (4-pyridine)methylene moiety to enhance the push-pull character of aromatic ring (Table 1) (Novohradsky and Rovira., 2019). The Ir(III)COUPY conjugate 48 was proven to be very promising photosensitizer suitable for photodynamic therapy (PDT) of cancers, including hypoxic tumors. For the first time it was demonstrated that such photo-induced therapy with metalbased compound 48 might provide a new approach for prostate cancer treatment due to the controlled cytotoxic effect by generation a specific type I ROS, superoxide anion radical, upon visible-light irradiation at a dose of $28 \mathrm{~J} \mathrm{~cm}^{-2}$ of $420 \mathrm{~nm}$ blue light (Novohradsky and Markova et al., 2021). The pronounced selectivity for tumor cells compared with noncancerous cells, as well as low toxicity in prostate cancer cell line DU145 in the dark $\left(\mathrm{IC}_{50 \text { (irrad.) }}=5.7 \mu \mathrm{M} v s \mathrm{IC}_{50 \text { (dark) }} \geq\right.$ $100 \mu \mathrm{M}$ ) could results in low side effects and reduced damage of normal cells during the PDT.

\section{ENZYME-MIMICKING COMPLEXES}

Due to the fact, that metal ions play a pivotal role in biological systems as centers of enzymes or metalloenzymes, transient metal complexes of small molecules may constitute a valid tool in the field of biochemistry and modern biosynthesis as enzyme mimetics.

The halo-peroxidase mimicking properties of oxidovanadium complexes 49-51 (Table 1) have been proved by Majumder et al. (Majumder and Rajak., 2020). The complexes were studied on a model catalytic bromination reaction of aromatic aldehydes. In this case, the oxidative conversions of aldehyde in the presence of hydrogen peroxide and potassium bromide in an aqueous medium were very effective.

In 2021, Sezgin and co-workers exploited two complexes $\left[\mathrm{Cu}(\mathrm{PYC})_{2}\left(\mathrm{H}_{2} \mathrm{O}\right)_{2}\right] 52$ and $\left[\mathrm{Mn}(\mathrm{PYC})_{2}\left(\mathrm{H}_{2} \mathrm{O}\right)_{2}\right] 53$ (Table 1) containing copper (II) and manganese (II) as catecholase-like or phenoxazinone synthase mimetics under aerobic conditions (Sezgin et al., 2021). The kinetic studies of enzymatic activity revealed that copper (II) complex was more effective than manganese (II) one and both complexes possess better catecholase-like activity than phenoxazinone synthase mimetic properties, These results indicate that complexes 52 and 53 represent a good starting point for the design of promising tools for the catecholase-like and phenoxazinone synthase-like activities.

\section{ENZYME INHIBITING COMPLEXES}

Şahin et al. demonstrated the inhibitory potency of palladium (II) and platinum (II) complexes of coumarin-based ligand - 3-\{2-[(3(tert-butyl)-2-hydroxybenzylidene)amino]thiazol-4-yl $\}$ -

2H-chromen-2-one 54 and 55 (Table 1) against acetylcholinesterase (AChE), butyrylcholinesterase (BChE), and pancreatic cholesterol esterase (cease) (Şahin et al., 2020). The inhibitory properties against AChE, BChE, and cease of synthesized complexes were determined by a standard procedure involving the spectrophotometric measurements according to Elman or Pietsch and Gütschow methods. It was found that $\mathbf{5 4}$ exhibited a strong inhibition towards acetylcholinesterase (AChE) with $\mathrm{IC}_{50}$ value of $16 \mu \mathrm{M}$, compared to the pyridostigmine bromide as a positive control $\left(\mathrm{IC}_{50}=23 \mu \mathrm{M}\right)$, whereas platinum complex 55 showed inhibitory activity on three esterases with following IC $_{50}$ values: $12 \mu \mathrm{M}$ (AChE), $23 \mu \mathrm{M}$ (BChE), and $21 \mu \mathrm{M}$ (cease). These results supported by Density Functional Theory (DFT) calculations are encouraging in the perspective of using coumarin-metal complexes with dual cholinesterase inhibition (AChE and $\mathrm{BChE)}$ as potential anti-Alzheimer agents.

Concerning the anti-AChE properties of coumarins, the structure-activity studies pointed out that the presence of an amide moiety in their structure may play important role in the enzyme inhibition (Asadipour et al., 2013; Ghanei-Nasab et al., 2016).

Karcz and collaborators evaluated a series of copper (II) and zinc(II) complexes of novel coumarin-thiadiazole hybrids as potential acetylcholinesterase inhibitors (Karcz et al., 2021). In this assay it was identified that the most active are the amidebearing complexes $56\left(\mathrm{IC}_{50}=0.174 \mu \mathrm{M}\right)$ and $57\left(\mathrm{IC}_{50}=\right.$ $0.184 \mu \mathrm{M})$, as well as the parent ligand - $N$-[5-(7-hydroxy-4methyl-2-oxo-2H-chromen-8-yl)-1,3,4-thiadiazol-2-yl]acetamide 
$\left(\mathrm{IC}_{50}=0.181 \mu \mathrm{M}\right)$. Despite the fact, that these hybrids exhibited about 4-fold weaker activities compared to that of the commercially available $\mathrm{AChE}$ inhibitor - tacrine $\left(\mathrm{IC}_{50}=\right.$ $0.053 \mu \mathrm{M})$, the result obtained set the direction for potential further modifications of this type of compounds in order to obtain their amide derivatives with higher antineurodegenerative potency. The observed significant decrease in solubility of metal complexes in relation to their free ligands suggests that future studies should also focus on their pharmacokinetic properties. In addition, since the AChE is not the only target in the treatment of the neurodegenerative process, new approaches ought to aim at a more detailed evaluation of the anti-neurodegenerative properties of these complexes, for example, the assessment of butyrylcholinesterase (BuChE) inhibiting activity, as well as amyloid fibrils suppression ability.

\section{COUMARIN-BASED METAL COMPLEXES AS FLUORESCENT PROBES/SENSORS}

Recently, the fluorescent methods of detection or monitoring of a variety of biologically important species such as biothiols or ions under physiological conditions in intracellular compartments (cell nucleus, mitochondria, and cytosol) have been developed. In this context the metal complexes of coumarins, which represent the electron-rich conjugated systems with strong fluorescent properties, have found important applications also in the selective detection of biomaterials, metals and ions.

Given the fact that altered cellular glutathione (GSH) levels are related to human diseases such as cancer, AIDS, cardiovascular or neurodegenerative disorders, in $2019 \mathrm{He}$ and others proposed a fluorescent probe for glutathione based on a copper complex of coumarin hydrazide Schiff base derivative (He et al., 2019). The fluorescent Schiff base ligand - $N^{3}$-[(1H-imidazol-2-yl)methylene]-7-(diethylamino)2-oxo-2H-chromene-3-carbohydrazide was reacted with copper (II) perchlorate $\left(\mathrm{Cu}\left(\mathrm{ClO}_{4}\right)_{2} \cdot 6 \mathrm{H}_{2} \mathrm{O}\right)$ yielding an appropriate copper (II) complex 58 (Table 2). First, it was observed that fluorescence quenching of ligand was induced by copper (II) ions and the fluorescence quenching effect was not disturbed by the presence of other metal ions. The mechanism of fluorescence quenching may be attributed to the photoinduced charge transfer (PCT). Then, the complex 58 was evaluated as a "turn-on" fluorescent probe for optical detection of glutathione (GSH). The test pointed out, that the stronger ability of GSH to capture copper (II) ions from complex 58 results in its demetallation and subsequent fluorescence restoration. The use of complex $\mathbf{5 8}$ gives the minimum detection limit of GSH about $0.12 \mu \mathrm{M}$.

In 2019, Li et al. reported formed "in situ" in acetonitrile and water mixture coumarin-based copper (II) complex 59 (Table 2) that may find application as a fluorescent turn-off chemosensor for colorimetric and fluorescent detection of biothiols: cysteine (Cys), homocysteine (Hcy), and glutathione (GSH) (Li et al., 2019). The high affinity of thiols to the $\mathrm{Cu}^{2+}$ results in the demetallation of the $\mathrm{Cu}$-complex 59. In turn, releasing of free ligand turn off the fluorescence, in contrast, to "turn-on" chemosensors for biothiols based on the demetallation of copper-complexes. The estimated detection limits for Cys, $\mathrm{Hcy}$, and GSH were in the range of $10-16 \mu \mathrm{M}$.

Concerning the fluorescent properties of copper (II) complexes with coumarin-based ligands, Cheng and collaborators developed an efficient fluorescent "turn-on" water sensors (Cheng et al., 2019). It was demonstrated that 7-R-2-oxo- $2 \mathrm{H}$-chromene-3-carboxylic acids $\left(\mathrm{R}=\mathrm{OH}, \mathrm{N}\left(\mathrm{C}_{2} \mathrm{H}_{5}\right)_{2}\right)$ in dry organic solvents generate "in situ" almost non-fluorescent copper (II) complexes 60 and 61 (Table 2), whereas in the presence of a trace of water complexes 60 and 61 exhibit bright emission.

In 2020, Luan and co-workers reported the synthesis of europium (III) complexes [EuL $\left(\mathrm{NO}_{3}\right)_{3} \cdot \mathrm{H}_{2} \mathrm{O}$ ] 62-64 (Table 2) based on the novel coumarin Schiff base derivatives, which exhibited characteristic red fluorescence and showed the influence of different substituents on the fluorescence properties of these complexes in order $\mathrm{OCH}_{3}>\mathrm{H}>\mathrm{NO}_{2}$. (Luan et al., 2020). Furthermore, it was demonstrated, that the characteristic red fluorescence intensity of complex 63 was significantly reduced in the presence of fluoride anion. The response limit in the range of $1.0 \cdot 10^{-5}-2.2 \cdot 10^{-5} \mathrm{~mol} \mathrm{~L}^{-1}$ clearly indicates that fluorescent europium (III) complex 63 may serve as a selective tool for fluoride anion detection.

Recently, photoelectrochemical (PEC) techniques based on metal complexes have been applied in the detection of diverse biological analytes. Coumarin-attached cyclometalated iridium (III) complex $\left[(\mathrm{CHO}-\text { bpy })_{2} \mathrm{Ir}(\mathrm{C}-\mathrm{phen})\right]^{+} \mathrm{PF}_{6}^{-} 65$ (Table 2) synthesized by $\mathrm{Li}$ et al. was proved as efficient PEC active material suitable in bioanalysis due to the enhanced absorption in the visible light ( $\mathrm{Li}$ et al., 2020). PEC sensor 65 exhibited enhanced fine selectivity and sensitivity for thrombin with the detection limit of $23 \mathrm{fM}$.

Finally, Di Pietro et al. synthesized coumarin-based dipicolinate europium complexes $\mathrm{Na}_{3}\left[\mathrm{Eu}\left(\mathrm{L}_{1}\right)_{3}\right] \mathbf{6 6}$ and $\mathrm{Na}_{3}$ [Eu $\left(\mathrm{L}_{2}\right)_{3}$ ] 67 (Table 2) (Di Pietro et al., 2021), which as either mono or dual emitter merge the excellent photophysical properties of the 2-oxo- $2 \mathrm{H}$-chromene chromophore and europium ion. Their simple synthesis and possible chemical modification give the opportunity to optimize their emission properties in constructing molecular probes.

\section{CONCLUSION}

In recent years, the considerable increase in the number of papers and reports describing the possible uses of coumarin-based metal complexes in therapy and medicine is a vivid demonstration of their impact on the scientific community. Coumarin-based complexes have also attracted attention due to their interesting fluorescent properties as sensors or probes.

In this mini-review we summarized the recent advances in coumarin-metal complexes as anticancer, antimicrobial, antifungal, or antioxidants agents as well as enzyme mimics or enzyme inhibitors from 2019 to 2021.

Having in mind a great need for new therapeutic agents for combating cancers, metal complexes with coumarin-based ligands have been extensively studied for their cytotoxic 
properties. The most promising coumarin-based compounds incorporating metal ions are bi-functional platinum (IV) complexes with COX inhibiting properties or $\operatorname{Ir}(\mathrm{III})$-COUPY conjugates as promising photosensitizers in photodynamic therapy targeting cancer stem cells.

On the other hand, with the rise in the number of multi-drug resistant microbial pathogens, the development of new antimicrobial agents is another main research in which coumarin-based metal complexes are evaluated.

The valuable and promising compounds incorporating coumarin-metal complexes are also those which may serve as lead compounds for developing anti-neurogenerative agents.

Moreover, the most recent advances on the synthesis of metal complexes with coumarin-based ligands include probes or sensors with practical applications for detecting diverse biological analytes under physiological conditions. Great interest has been made towards the development of coumarin-based copper (II), iridium (III) or europium (III) complexes as fluorescent probes or PEC sensors for bioanalysis.

\section{REFERENCES}

Akkol, E. K., Genç, Y., Karpuz, B., Sobarzo-Sánchez, E., and Capasso, R. (2020). Coumarins and Coumarin-Related Compounds in Pharmacotherapy of Cancer. Cancers 12, 1959. doi:10.3390/cancers12071959

Akpunar, C., Özdemir, N., Karataş, M. O., Alıcı, B., and Özdemir, İ. (2021). Synthesis, crystal Structures and Catalytic Activities of Palladium Complexes with Coumarin-Functionalised N-Heterocyclic Carbene Ligands. Inorg. Chem. Commun. 131, 108755. doi:10.1016/ j.inoche.2021.108755

Al-Warhi, T., Sabt, A., Elkaeed, E. B., and Eldehna, W. M. (2020). Recent Advancements of Coumarin-Based Anticancer Agents: an Up-To-Date Review. Bioorg. Chem. 103, 104163. doi:10.1016/j.bioorg.2020.104163

Annunziata, F., Pinna, C., Dallavalle, S., Tamborini, L., and Pinto, A. (2020). An Overview of Coumarin as a Versatile and Readily Accessible Scaffold with Broad-Ranging Biological Activities. Ijms 21:4618. doi:10.3390/ ijms2 1134618

Asadipour, A., Alipour, M., Jafari, M., Khoobi, M., Emami, S., Nadri, H., et al. (2013). Novel Coumarin-3-Carboxamides Bearing N-Benzylpiperidine Moiety as Potent Acetylcholinesterase Inhibitors. Eur. J. Med. Chem. 70, 623-630. doi:10.1016/j.ejmech.2013.10.024

Avdović, E. H., Stojković, D. L., Jevtić, V. V., Milenković, D., Marković, Z. S., Vuković, N., et al. (2019). Preparation and Antimicrobial Activity of a New Palladium(II) Complexes with a Coumarin-Derived Ligands. Crystal Structures of the 3-(1-(o-Toluidino)ethylidene)-Chroman-2,4-Dione and 3-(1(m-Toluidino) Ethylidene)-Chroman-2,4-Dione. Inorg. Chim. Acta 484, 52-59. doi:10.1016/j.ica.2018.09.014

Balcıoğlu, S., Olgun Karataş, M., Ateş, B., Alıcı, B., and Özdemir, İ. (2020). Therapeutic Potential of Coumarin Bearing Metal Complexes: Where Are We Headed? Bioorg. Med. Chem. Lett. 30, 126805. doi:10.1016/ j.bmcl.2019.126805

Belkhir-Talbi, D., Makhloufi-Chebli, M., Terrachet-Bouaziz, S., Hikem-Oukacha, D., Ghemmit, N., Ismaili, L., et al. (2019). Synthesis, Characterization, Theoretical Studies, ADMET and Drug-Likeness Analysis: Electrochemical and Biological Activities of Metal Complexes of 3-(2-Hydroxybenzoyl)-2h-Chromen-2-One. J. Mol. Struct. 1179, 495-505. doi:10.1016/j.molstruc.2018.11.035

Boros, E., Dyson, P. J., and Gasser, G. (2020). Classification of Metal-Based Drugs According to Their Mechanisms of Action. Chem 6, 41-60. doi:10.1016/ j.chempr.2019.10.013

Boyar, C. Y., and Çamur, M. (2019). Novel Water Soluble 7-Oxy-4-(pyridine-3-Yl) coumarin Substituted Phthalocyanines as Potential Photosensitizers for
Summing up, the reported studies and some others outside the scope of this mini-review (i.e. light-emitting diodes (Feng et al., 2019; Feng et al., 2020; Yang et al., 2021), catalysts (Dharani et al., 2019; Akpunar et al., 2021; Gautam et al., 2021; Karataş et al., 2021) evident the great potential of coumarin-metal complexes in different fields of research. We hope that this mini-review will be useful in the further development of coumarin-based metal complexes in drug design and fluorescence probes.

\section{AUTHOR CONTRIBUTIONS}

Concept: AK; literature research: $\mathrm{\iota B}$ and $\mathrm{AJ}$; original draft preparation: $€ B$ and SS; writing review and editing: $€ B, S S$ and $\mathrm{AK}$; supervision: $\mathrm{AK}$ and $€ B$.

\section{FUNDING}

We thank financial support from Medical University of Gdańsk.

Photodynamic Therapy. Inorg. Chim. Acta 494, 30-41. doi:10.1016/ j.ica.2019.05.004

Carneiro, A., Matos, M. J., Uriarte, E., and Santana, L. (2021). Trending Topics on Coumarin and its Derivatives in 2020. Molecules 26, 501. doi:10.3390/ molecules26020501

Cheng, W., Xie, Y., Yang, Z., Sun, Y., Zhang, M.-Z., Ding, Y., et al. (2019). General Strategy for In Situ Generation of a Coumarin-Cu2+ Complex for Fluorescent Water Sensing. Anal. Chem. 91, 5817-5823. doi:10.1021/ acs.analchem.9b00132

Claudel, M., Schwarte, J. V., and Fromm, K. M. (2020). New Antimicrobial Strategies Based on Metal Complexes. Chemistry 2, 849-899. doi:10.3390/ chemistry2040056

De Almeida, P. S. V. B., Pereira, T. M., Kummerle, A. E., Guedes, G. P., Silva, H., de Oliveira, L. L., et al. (2019). New Ru(II)-DMSO Complexes Containing Coumarin-N-Acylhydrazone Hybrids: Synthesis, X-ray Structures, Cytotoxicity and Antimicrobial Activities. Polyhedron 171, 20-31. doi:10.1016/j.poly.2019.06.053

Dharani, S., Kalaiarasi, G., Sindhuja, D., Lynch, V. M., Shankar, R., Karvembu, R., et al. (2019). Tetranuclear Palladacycles of 3-Acetyl-7-Methoxy-2h-Chromen2-One Derived Schiff Bases: Efficient Catalysts for Suzuki-Miyaura Coupling in an Aqueous Medium. Inorg. Chem. 58, 8045-8055. doi:10.1021/ acs.inorgchem.9b00794

Di Pietro, S., Iacopini, D., Moscardini, A., Bizzarri, R., Pineschi, M., Di Bussolo, V., et al. (2021). New Coumarin Dipicolinate Europium Complexes with a Rich Chemical Speciation and Tunable Luminescence. Molecules 26, 1265. doi:10.3390/molecules26051265

Feng, Z., Yu, Y., Yang, X., Wu, Y., Zhou, G., and Wu, Z. (2020). Unsymmetric Heteroleptic Ir(III) Complexes with 2-phenylquinoline and Coumarin-Based Ligand Isomers for Tuning Character of Triplet Excited States and Achieving High Electroluminescent Efficiencies. Inorg. Chem. 59, 12362-12374. doi:10.1021/acs.inorgchem.0c01443

Feng, Z., Yu, Y., Yang, X., Zhong, D., Song, D., Yang, H., et al. (2019). Isomers of Coumarin-Based Cyclometalated Ir(III) Complexes with Easily Tuned Phosphorescent Color and Features for Highly Efficient Organic LightEmitting Diodes. Inorg. Chem. 58, 7393-7408. doi:10.1021/ acs.inorgchem.9b00534

Frei, A. (2020). Metal Complexes, an Untapped Source of Antibiotic Potential? Antibiotics 9, 90. doi:10.3390/antibiotics9020090

Garg, S. S., Gupta, J., Sharma, S., and Sahu, D. (2020). An Insight into the Therapeutic Applications of Coumarin Compounds and Their Mechanisms of Action. Eur. J. Pharm. Sci. 152, 105424. doi:10.1016/ j.ejps.2020.105424 
Gasser, G., and Metzler-Nolte, N. (2012). The Potential of Organometallic Complexes in Medicinal Chemistry. Curr. Opin. Chem. Biol. 16, 84-91. doi:10.1016/j.cbpa.2012.01.013

Gautam, A., Shahini, C. R., Siddappa, A. P., Jan Grzegorz, M., Hemavathi, B., Ahipa, T. N., et al. (2021). Palladium(II) Complexes of Coumarin Substituted 1,2,4-Triazol-5-Ylidenes for Catalytic C-C Cross-Coupling and C-H Activation Reactions. J. Organomet. Chem. 934, 121540. doi:10.1016/ j.jorganchem.2020.121540

Geetha, B. M., Brinda, K. N., Achar, G., Małecki, J. G., Alwarsamy, M., Betageri, V. S., et al. (2020). Coumarin Incorporated 1,2,4-triazole Derived Silver(I) $\mathrm{N}$-Heterocyclic Carbene Complexes as Efficient Antioxidant and Antihaemolytic Agents. J. Mol. Liquids 301, 112352. doi:10.1016/ j.molliq.2019.112352

Geetha, B. M., Małecki, J. G., Alwarsamy, M., Keri, R. S., Betageri, V. S., and Budagumpi, S. (2020). Coumarin Substituted 4-Aryl-1,2,4-Triazolium Salts and Their Silver(I) N-Heterocyclic Carbene Complexes: Effects of Counterions on the Antioxidant and Antihaemolytic Properties. J. Mol. Liquids 316, 113809. doi:10.1016/j.molliq.2020.113809

Ghanei-Nasab, S., Khoobi, M., Hadizadeh, F., Marjani, A., Moradi, A., Nadri, H., et al. (2016). Synthesis and Anticholinesterase Activity of Coumarin-3Carboxamides Bearing Tryptamine Moiety. Eur. J. Med. Chem. 121, 40-46. doi:10.1016/j.ejmech.2016.05.014

Gramni, L., Vukea, N., Chakraborty, A., Samson, W. J., Dingle, L. M. K., Xulu, B., et al. (2019). Anticancer Evaluation of Ruthenium(III) Complexes with N-Donor Ligands Tethered to Coumarin or Uracil Moieties. Inorg. Chim. Acta 492, 98-107. doi:10.1016/j.ica.2019.04.018

He, G., Hua, X., Yang, N., Li, L., Xu, J., Yang, L., et al. (2019). Synthesis and Application of a "Turn on" Fluorescent Probe for Glutathione Based on a Copper Complex of Coumarin Hydrazide Schiff Base Derivative. Bioorg. Chem. 91, 103176. doi:10.1016/j.bioorg.2019.103176

Ibrahim, D. M., Jumal, J., and Al-Adiwish, W. M. (2019). Anti-cancer Screening of Some Transition Metal Ion Complexes with Coumarin Derivatives. J. Transit. Met Complexes 2, 1-5. doi:10.32371/jtmc/236074

Karataş, M. O., Alıcı, B., Passarelli, V., Özdemir, I., Pérez-Torrente, J. J., and Castarlenas, R. (2021). Iridium(I) Complexes Bearing Hemilabile CoumarinFunctionalised $\mathrm{N}$-Heterocyclic Carbene Ligands with Application as Alkyne Hydrosilylation Catalysts. Dalton Trans. 50, 11206-11215. doi:10.1039/ d1dt01946e

Karcz, D., Starzak, K., Ciszkowicz, E., Lecka-Szlachta, K., Kamiński, D., Creaven, B., et al. (2021). Novel Coumarin-Thiadiazole Hybrids and Their $\mathrm{Cu}(\mathrm{II})$ and $\mathrm{Zn}$ (II) Complexes as Potential Antimicrobial Agents and Acetylcholinesterase Inhibitors. Ijms 22, 9709. doi:10.3390/ijms22189709

Kim, Y. S., Kang, M. J., and Cho, Y. M. (2013). Low Production of Reactive Oxygen Species and High DNA Repair: Mechanism of Radioresistance of Prostate Cancer Stem Cells. Anticancer Res. 33, 4469-4474.

Li, C., Cai, Y., Pang, M., Zhou, X., Luo, X., and Xiao, Z. (2020). A CoumarinAppended Cyclometalated Iridium(III) Complex for Visible Light Driven Photoelectrochemical Bioanalysis. Biosens. Bioelectron. 147, 111779. doi:10.1016/j.bios.2019.111779

Li, H., Sun, X., Zheng, T., Xu, Z., Song, Y., and Gu, X. (2019). Coumarin-based Multifunctional Chemosensor for Arginine/lysine and $\mathrm{Cu}^{2+} / \mathrm{Al}^{3+}$ Ions and its $\mathrm{Cu}^{2+}$ Complex as Colorimetric and Fluorescent Sensor for Biothiols. Sensors Actuators B: Chem. 279, 400-409. doi:10.1016/j.snb.2018.10.017

Lu, W., Shi, J., Nie, Y., Yang, L., Chen, J., Zhao, F., et al. (2020). Synthesis, crystal Structure, Antiproliferative Activity, DNA Binding and Density Functional Theory Calculations of 3-(pyridin-2-Yl)-8-Tert-Butylcoumarin and its Copper(II) Complex. Appl. Organomet. Chem. 34, e5875. doi:10.1002/ aoc. 5875

Luan, F., Xiao, G., Zhang, Y., Li, S., Hu, Z., Du, H., et al. (2020). Synthesis, Fluorescence Properties and F- Detection Performance of Eu(III) Complexes Based on the Novel Coumarin Schiff Base Derivatives. J. Mol. Liquids 320, 114439. doi:10.1016/j.molliq.2020.114439

Majumder, M., and Krishna Rajak, K. (2020). Oxidovanadium (V and IV) Complexes Incorporating Coumarin Based ONO Ligand: Synthesis, Structure and Catalytic Activities. Polyhedron 176, 114241. doi:10.1016/ j.poly.2019.114241

Mestizo, P. D., Narváez, D. M., Pinzón-Ulloa, J. A., Di Bello, D. T., Franco-Ulloa, S., Macías, M. A., et al. (2021). Novel Complexes with ONNO Tetradentate
Coumarin Schiff-Base Donor Ligands: X-ray Structures, DFT Calculations, Molecular Dynamics and Potential Anticarcinogenic Activity. Biometals 34, 119-140. doi:10.1007/s10534-020-00268-8

Milenković, D. A., Dimić, D. S., Avdović, E. H., and Marković, Z. S. (2020). Several Coumarin Derivatives and Their Pd(II) Complexes as Potential Inhibitors of the Main Protease of SARS-CoV-2, an In Silico Approach. RSC Adv. 10, 35099-35108. doi:10.1039/D0RA07062A

Mishra, S., Pandey, A., and Manvati, S. (2020). Coumarin: an Emerging Antiviral Agent. Heliyon 6, e03217. doi:10.1016/j.heliyon.2020.e03217

Noffke, A. L., Habtemariam, A., Pizarro, A. M., and Sadler, P. J. (2012). Designing Organometallic Compounds for Catalysis and Therapy. Chem. Commun. 48, 5219-5246. doi:10.1039/c2cc30678f

Nongpiur, C. G. L., Dkhar, L., Tripathi, D. K., Poluri, K. M., Kaminsky, W., and Kollipara, M. R. (2021). Half-sandwich Platinum Group Metal Complexes Containing Coumarin-N-Acylhydrazone Hybrid Ligands: Synthesis and Biological Evaluation Studies. Inorg. Chim. Acta 525, 120459. doi:10.1016/ j.ica.2021.120459

Novohradsky, V., Markova, L., Kostrhunova, H., Kasparkova, J., Ruiz, J., Marchán, V., et al. (2021). A Cyclometalated Ir III Complex Conjugated to a Coumarin Derivative Is a Potent Photodynamic Agent against Prostate Differentiated and Tumorigenic Cancer Stem Cells. Chem. Eur. J. 27, 8547-8556. doi:10.1002/ chem.202100568

Novohradsky, V., Rovira, A., Hally, C., Galindo, A., Vigueras, G., Gandioso, A., et al. (2019). Towards Novel Photodynamic Anticancer Agents Generating Superoxide Anion Radicals: A Cyclometalated Ir III Complex Conjugated to a Far-Red Emitting Coumarin. Angew. Chem. Int. Ed. 58, 6311-6315. doi:10.1002/anie.201901268

Özdemir, M., Abliatipova, A., Benian, S., Yalçın, B., Salan, Ü., Durmuş, M., et al. (2020). 1,2,3-Triazole Incorporated Coumarin Carrying Metal-free, $\mathrm{Zn}(\mathrm{II}), \mathrm{Mg}$ (II) Phthalocyanines: Synthesis, Characterization, Theoretical Studies, Photophysical and Photochemical Properties. J. Photochem. Photobiol. A: Chem. 403, 112845-112855. doi:10.1016/ j.jphotochem.2020.112845

Özdemir, M., Köksoy, B., Yalçın, B., Taşkın, T., Selçuki, N. A., Salan, Ü., et al. (2021). Novel Lutetium(III) Phthalocyanine-Coumarin Dyads; Synthesis, Characterization, Photochemical, Theoretical and Antioxidant Properties. Inorg. Chim. Acta 517, 120145. doi:10.1016/j.ica.2020.120145

Parveen, S., Arjmand, F., and Tabassum, S. (2019). Development and Future Prospects of Selective Organometallic Compounds as Anticancer Drug Candidates Exhibiting Novel Modes of Action. Eur. J. Med. Chem. 175, 269-286. doi:10.1016/j.ejmech.2019.04.062

Patel, G., and Banerjee, S. (2020). Review on Synthesis of Bio-Active CoumarinFused Heterocyclic Molecules. Coc 24, 2566-2587. doi:10.2174/ 1385272824999200709125717

Pereira, T. M., Franco, D. P., Vitorio, F., and Kummerle, A. E. (2018). Coumarin Compounds in Medicinal Chemistry: Some Important Examples from the Last Years. Ctmc 18, 124-148. doi:10.2174/1568026618666180329115523

Qian, X., Nie, X., Yao, W., Klinghammer, K., Sudhoff, H., Kaufmann, A. M., et al. (2018). Reactive Oxygen Species in Cancer Stem Cells of Head and Neck Squamous Cancer. Semin. Cancer Biol. 53, 248-257. doi:10.1016/ j.semcancer.2018.06.001

Şahin, Ö., Özmen Özdemir, Ü., Seferoğlu, N., Adem, Ş., and Seferoğlu, Z. (2020). Synthesis, Characterization, Molecular Docking and In Vitro Screening of New Metal Complexes with Coumarin Schiff Base as Anticholine Esterase and Antipancreatic Cholesterol Esterase Agents. J. Biomol. Struct. Dyn., 1-15. doi:10.1080/07391102.2020.1858163

Sarkar, T., Kumar, A., Sahoo, S., and Hussain, A. (2021). Mixed-ligand Cobalt(III) Complexes of a Naturally Occurring Coumarin and Phenanthroline Bases as Mitochondria-Targeted Dual-Purpose Photochemotherapeutics. Inorg. Chem. 60, 6649-6662. doi:10.1021/ acs.inorgchem.1c00444

Sezgin, B., Dede, B., and Tilki, T. (2021). Structural, Theoretical and Enzyme-like Activities of Novel $\mathrm{Cu}(\mathrm{II})$ and $\mathrm{Mn}(\mathrm{II})$ Complexes with Coumarin Based Bidentate Ligand. Inorg. Chim. Acta 524, 120430. doi:10.1016/ j.ica.2021.120430

Song, X. F., Fan, J., Liu, L., Liu, X. F., and Gao, F. (2020). Minireview - Coumarin Derivatives with Anticancer Activities: An Update. Arch. Pharm. 353, 2000025. doi:10.1002/ardp.202000025 
Souza, D. A. G. d., Tranquilin, R. L., Santos, M. L. d., and Pereira, R. M. S. (2021). Synthesis of $\mathrm{Ni}(\mathrm{II}), \mathrm{Cu}(\mathrm{II})$ and $\mathrm{Zn}(\mathrm{II})$ Coumarin-3-Carboxilic Acid Derivates and Their and Their Physical-Chemical Properties. Rsd 10 (3), e47910313430. doi:10.33448/rsd-v10i3.13430

Srikrishna, D., Godugu, C., and Dubey, P. K. (2018). A Review on Pharmacological Properties of Coumarins. Mrmc 18, 113-141. doi:10.2174/ 1389557516666160801094919

Stefanachi, A., Leonetti, F., Pisani, L., Catto, M., and Carotti, A. (2018). Coumarin: a Natural, Privileged and Versatile Scaffold for Bioactive Compounds. Molecules 23, 250. doi:10.3390/molecules23020250

Wang, Q., Chen, Y., Li, G., Liu, Z., Ma, J., Liu, M., et al. (2019). Synthesis and Evaluation of Bi-functional 7-hydroxycoumarin Platinum(IV) Complexes as Antitumor Agents. Bioorg. Med. Chem. 27, 2112-2121. doi:10.1016/j.bmc.2019.04.009

Yang, S., Guo, Z., Hu, Z., and Guo, D. (2021). Novel Intramolecular Charge Transfer Effect-based Ligands and Aggregation-induced Emission-active Europium Complexes: Synthesis, Characterization, and Fluorescence Properties. Luminescence 36, 306-315. doi:10.1002/bio.3925

Yernale, N. G., and Bennikallu Hire Mathada, M. (2020). Preparation of Octahedral $\mathrm{Cu}(\mathrm{II}), \mathrm{Co}(\mathrm{II}), \mathrm{Ni}(\mathrm{II})$ and $\mathrm{Zn}(\mathrm{II})$ Complexes Derived from 8Formyl-7-Hydroxy-4-Methylcoumarin: Synthesis, Characterization and
Biological Study. J. Mol. Struct. 1220, 128659. doi:10.1016/ j.molstruc.2020.128659

Conflict of Interest: The authors declare that the research was conducted in the absence of any commercial or financial relationships that could be construed as a potential conflict of interest.

Publisher's Note: All claims expressed in this article are solely those of the authors and do not necessarily represent those of their affiliated organizations, or those of the publisher, the editors and the reviewers. Any product that may be evaluated in this article, or claim that may be made by its manufacturer, is not guaranteed or endorsed by the publisher.

Copyright (c) 2021 Balewski, Szulta, Jalinska and Kornicka. This is an open-access article distributed under the terms of the Creative Commons Attribution License (CC $B Y$ ). The use, distribution or reproduction in other forums is permitted, provided the original author(s) and the copyright owner(s) are credited and that the original publication in this journal is cited, in accordance with accepted academic practice. No use, distribution or reproduction is permitted which does not comply with these terms. 